\title{
Assessing priorities for allocation of donor liver grafts: survey of public and clinicians
}

\author{
James Neuberger, David Adams, Paul MacMaster, Anita Maidment, Mark Speed
}

\begin{abstract}
Liver Unit, Queen Elizabeth Hospital, Birmingham B15 2TH James Neuberger, consultant physician David Adams, professor of hepatology Paul MacMaster, professor of surgery

MORI, London SE1 0HX

Anita Maidment senior research executive

Mark Speed, research director

Correspondence to: Dr Neuberger james.neuberger@ university-b.umsds. nhs.uk
\end{abstract}

BMJ 1998;317:172-5

\begin{abstract}
Objectives: To compare the priorities of the general public, family doctors, and gastroenterologists in allocating donor livers to potential recipients of liver allograft.

Design: Representative quota sampling of 1000 members of the general public and 200 family doctors, and a postal questionnaire of 100 gastroenterologists. Subjects: Respondents were given eight hypothetical case histories (based on real patients) and asked to select recipients for four donor livers. Cases were selected to identify controversial areas such as extremes of age, misuse of alcohol, and intravenous drugs. Respondents were also asked to select the least deserving case and which of seven possible factors (time on waiting list, outcome, age, value to society, return to work, previous use of illicit drugs, and involvement of alcohol in the liver damage) should be used to select patients already listed for transplantation. Focus groups were also held to explore further the reasons for the choices given. Results: There were considerable differences between the three groups in the choice of the recipients, although alcohol use and antisocial behaviour always rated low. For selection of recipients the general public thought that, in decreasing order of importance, age, outcome, and time on the waiting list were the most important factors in selecting recipients; family doctors rated outcome, age, and likely work status after transplantation and the gastroenterologists outcome, work status, and non-involvement of alcohol in the cause of the liver disease as the most important factors.

Conclusions: The views of the public are at variance with those of clinicians. Further debate is required to ensure an equitable and appropriate distribution of a scarce resource.
\end{abstract}

\section{Introduction}

The number of patients being referred and accepted for liver transplantation is increasing. Thus, in the United Kingdom at the end of each year the number of patients waiting for a graft has increased from 83 in 1992 to 193 in 1996, despite an increase in the number of cadaveric liver transplants being done. ${ }^{1}$ Similar findings are reported from North America, ${ }^{2}$ where between 1992 and 1996 the number of patients waiting for a liver graft at the end of the year increased from 2323 to 7467 while the number of cadaveric transplants done increased from 3031 to 4012. The United Network for Organ Sharing (UNOS) has drawn up guidelines for placing patients on the waiting list ${ }^{3}$; introduction of these minimal listing criteria has been controversial. ${ }^{5}$ In the United Kingdom there are no central guidelines for accepting patients for transplantation.

The World Health Organisation has endorsed a series of guiding principles on organ transplantation. ${ }^{6}$
The ninth principle was "donated organs should be made available to patients on the basis of medical need and not on the basis of financial or other considerations." The relative shortage of donor livers, however, means that medical need cannot be the only criterion used to select patients for transplantation. We therefore took the example of the Oregon Health Services Commission $^{7}$ and sought the views of the public on perceived priorities on allocating organs to recipients. We also asked family doctors, who have close involvement with the patients, and hospital gastroenterologists, the main source of referral to the transplant centres.

\section{Methods}

The questionnaire was designed by the clinicians in conjunction with MORI (Market and Opinion Research International); to ensure that the questions were understood by non-clinicians, questions were brief and simplified.

\section{Selection of patients}

Respondents were given eight case histories and asked to select four recipients. Respondents were informed that, except where stated, all patients would have a good chance of living a normal life for at least another 10 years after transplantation and, except where indicated, the liver disease was not related to alcohol. The case histories, which had not been piloted before undertaking the questionnaire, were selected to highlight specific problems and are all based on patients referred to us. The focus of the question is indicated in parentheses for simpler reporting of results.

- A 68 year old woman looks after her 92 year old father at home. She has a serious liver disease and will die within 6 months without the transplant (upper age limit)

- A 9 month old boy has liver disease. Without a transplant he will die in 18 months. He has three older brothers and one older sister (lower age limit)

- A 21 year old woman is diagnosed with liver cancer when 8 months' pregnant. She will die in 6 months without the transplant. If transplanted, she has only a one in two chance of being present at her daughter's 1 st birthday party but a one in 10 chance of a cure and living for 10 or more years (emotional)

- A 17 year old woman takes a paracetamol overdose after a row with her boyfriend. It is the first time she has done this. Without the transplant she will be dead in 4 days (overdose)

- A 50 year old man is in prison serving a long sentence for grievous bodily harm. He has a serious liver disease from which he will die in 9 months (criminal record)

- A 45 year old garage owner with a wife and two young children has drunk heavily since he was 18 . This has led to liver and kidney failure. He has 2 months to live if he is not transplanted (alcohol) 
- A 35 year old unemployed man lives alone. His liver disease will kill him within 9 months unless he receives a transplant (contribution to society)

- A 45 year old woman used drugs in the 1970s during which she contracted a virus which resulted in liver failure. She has not used drugs since and unless transplanted is unlikely to live more than a year (previous drug user).

In addition to the case histories, respondents were also asked to identify which patient least deserved a graft.

Factors used to select listed patients

Respondents were asked to select four of seven possible criteria that should be used for allocation.

- Time on waiting list-patients who have waited longer should be given priority

- Age-patients aged under 5 years should be given priority

- "Value to society"-those of "value to society" would get high priority and those of less value would get lower priority

- Alcohol consumption-patients whose liver disease is unrelated to alcohol would be a higher priority than those who have alcohol related liver disease

- Work status-those who are likely to return to paid work or caring for family after transplant would get priority

- Outcome of transplant-patients likely to live longest after transplant will get priority

- Drugs-patients whose liver disease is unrelated to an overdose or taking illegal drugs would receive a higher priority than those whose liver disease is related to drug abuse.

\section{Respondent selection}

General public-The fieldwork for the general public was carried out between 11 and 14 April 1997. Personal interviews were conducted with a nationally representative quota sample of 1000 people aged 15 and above. The quota sample used is based on a 10 cell quota for sex, household tenure, age, and work status. The final sample was weighted on a series of additional factors-rim weights for social class, standard region, unemployment within region, cars in household, and age within sex. Of the sample, $37 \%$ were aged below 34 years, $49 \%$ were male, $21 \%$ were social class $\mathrm{AB}, 51 \%$ class $\mathrm{C} 1 / \mathrm{C} 2,28 \%$ class DE, 32\% had children in the household, $61 \%$ were married or living together, $32 \%$ had no educational qualifications, $30 \%$ had GCSE or NVQ, and 24\% A levels or above. With respect to annual household income $22 \%$ had less than $£ 9500$ and $14 \%$ above $£ 30000$.

Family doctors-The field work was carried out by NOP (National Opinion Polls) between 1 and 14 April 1997; personal face to face interviews were conducted with a nationally representative sample of 200 family doctors in Great Britain. Quotas were based on region with one practitioner per practice; within regions the selection of practices was random. Of the family doctors questioned, $84 \%$ were men, $47 \%$ were qualified before 1975, 43\% were fund holders, 19\% were in single handed practices, and $11 \%$ were in dispensing practices. Of the total, $32 \%$ had referred or looked after patients after liver transplantation.
Gastroenterologists-Senior gastroenterologists looking after adult or paediatric patients but working outside designated transplant units and resident in the United Kingdom were identified from the membership of the British Society of Gastroenterology (JN); 100 were selected at random by MORI and sent a postal questionnaire between 1 April 1997 and 12 May 1997; the response rate of analysable answers was $78 \%$. Of those who responded, $96 \%$ were men and 31\% started their specialist training in gastroenterology before 1975 .

\section{Statistics}

Data from the three surveys were ranked and rankings were correlated with the Spearman rank correlation coefficient.

\section{Results}

\section{Selection of patients}

The three groups indicated different priorities (table 1). In all three groups the man with alcoholic liver disease and the prisoner were given low priority. There was a correlation between the rankings given by the general public and the family doctors $(r=0.88)$ and between the family doctors and the gastroenterologists $(r=0.76)$ but not between the general public and the gastroenterologists $(r=0.48)$. When subjects were asked which patient least deserved a liver, however, the patient with alcoholic liver disease and the prisoner were the two most selected patients (table 2). There was no significant correlation between the rankings of the three groups.

For the responses by the general public there were no significant differences according to location in the

Table 1 Selection of four hypothetical patients to receive a donor liver. Respondents were asked to choose patients to receive one of four available donor livers. Values are percentages of respondents

\begin{tabular}{|c|c|c|c|}
\hline Detail of patient & $\begin{array}{l}\text { General public* } \\
\qquad(\mathrm{n}=1000)\end{array}$ & $\begin{array}{l}\text { Family doctors } \dagger \\
\qquad(\mathrm{n}=200)\end{array}$ & $\begin{array}{l}\text { Gastroenterologists } \\
(n=100)\end{array}$ \\
\hline 68 year old woman & 38 & 26 & 21 \\
\hline 9 month old boy & 78 & 82 & 64 \\
\hline Liver cell cancer & 74 & 57 & 45 \\
\hline Paracetamol overdose & 47 & 81 & 95 \\
\hline Prisoner & 2 & 7 & 9 \\
\hline Alcoholic liver disease & 16 & 18 & 19 \\
\hline Unemployed man & 56 & 67 & 74 \\
\hline Former drug misuser & 17 & 41 & 76 \\
\hline
\end{tabular}

${ }^{\star}$ Of the general public, 15 said all were equally important; two did not know.

tOf the family doctors, six indicated that all were equally deserving.

Table 2 Hypothetical patient selected by each group to be least deserving for graft. Values are percentages of respondents

\begin{tabular}{lccc} 
Detail of patient & $\begin{array}{c}\text { General public* } \\
(\mathbf{n = 1 0 0 0 )}\end{array}$ & $\begin{array}{c}\text { Family doctors } \\
(\mathbf{n}=\mathbf{2 0 0})\end{array}$ & $\begin{array}{c}\text { Gastroenterologists } \\
(\mathbf{n = 1 0 0 )}\end{array}$ \\
\hline 68 year old woman & 7 & 7 & 15 \\
\hline 9 month old boy & 3 & 5 & 5 \\
\hline Liver cell cancer & 1 & 7 & 13 \\
\hline Paracetamol overdose & 6 & 1 & 0 \\
\hline Prisoner & 33 & 27 & 34 \\
\hline Alcoholic liver disease & 17 & 40 & 33 \\
\hline Unemployed man & 2 & 1 & 0 \\
\hline Former drug misuser & 10 & 3 & 0
\end{tabular}

${ }^{*}$ Of the general public, 12 thought all were equally important or did not express preference and 10 did not know.

†Of the family doctors, seven thought that all were equally important or did not express preference and five did not know. 
Table 3 Criteria used to select patients listed for liver transplantation. Respondents were asked to identify four factors of seven which should be used to select liver transplant candidates when suitable donor became available. Values are percentages of respondents but exclude responses of "don't know" or when respondents gave fewer than four choices

\begin{tabular}{lccc} 
Criteria & $\begin{array}{c}\text { General public } \\
(\mathbf{n = 1 0 0 0 )}\end{array}$ & $\begin{array}{c}\text { Family doctors } \\
(\mathbf{n}=\mathbf{2 0 0})\end{array}$ & $\begin{array}{c}\text { Gastroenterologists } \\
(\mathbf{n = 1 0 0})\end{array}$ \\
\hline Time on waiting list & 63 & 45 & 49 \\
\hline Age & 76 & 82 & 38 \\
\hline Value to society & 20 & 31 & 31 \\
\hline Alcohol consumption & 28 & 41 & 68 \\
\hline Work status & 44 & 57 & 77 \\
\hline Outcome & 65 & 90 & 92 \\
\hline Drugs & 30 & 36 & 36
\end{tabular}

United Kingdom, age, sex, income, social class, educational qualifications, or voting intention. Similarly for the family doctors there were no differences of note according to location, type of practice, or year of qualification.

\section{Criteria to select recipients}

There was a clear variation in priorities between the three groups. While the general public thought that priority should be given to younger children, those with a better outcome, and those who had waited longest the gastroenterologists gave highest priority to outcome alone. The family doctors put priorities intermediate between the two other groups (table 3).

\section{Discussion}

\section{Best use of a limited resource}

The debate about rationing of health care has been focused primarily on funding issues, although other issues are clearly involved. ${ }^{8}$ The current need for rationing of liver transplantation has arisen not primarily as a consequence of financial restrictions but rather because of the lack of suitable donor organs. As with many other areas of health care where rationing has been necessary there has been little public discussion. There is controversy about whether the central government, local authorities, and health purchasers are able to define the criteria for allocation of a scarce resource or are the appropriate organisations to do so $^{10}{ }^{11}$; the decisions about who to refer for transplantation and who to offer a suitable graft have been left to the healthcare professionals. The public, however, should be involved in defining the principles underlying the allocation of organs. ${ }^{12}$ A study in the United States found that those members of the public who elected not to donate organs had little trust in the fairness of organ allocation and uncertainties about the success of transplantation. ${ }^{13}$

\section{Key messages}

- The shortage of donor livers means that rationing of the scarce resource is required

- The priorities of the public differ from those of the medical profession

- The public tend to prioritise on a more emotional basis and rank those with antisocial behaviour lowest

- There needs to be more discussion and agreement about the priorities for allocation of scarce resources

\section{Which criteria should be used?}

The American Medical Association listed acceptable criteria for selection of patients for organ transplantation: likelihood of benefit for the patient, importance of the treatment in improving the quality of the patient's life, duration of benefit, urgency of treatment, and amount of resources likely to be required. ${ }^{14}$ There were five unacceptable criteria: ability to pay, contribution of the patient to society, perceived obstacles to treatment (such as alcohol abuse, transport difficulties, antisocial personality), the contribution by the patient to his or her medical condition (such as alcohol abuse, intravenous drug abuse), and past use of medical resources. It is clear from this study that neither the general public nor the medical profession fully share these ideals.

Should the liver be allocated on the basis of greatest need or greatest benefit ${ }^{15}$ Does a patient whose illness is self induced, whether by alcohol, behaviour, or illicit drugs, have the same claim on a limited resource as patients who have no responsibility for their illness? Do older patients have the same claim on scarce resources as younger ones, even though the younger ones are likely to benefit more in the longer term. If there is an age limit, how should this be defined when survival rates in older patients are similar to those in younger ones? ${ }^{16} 17$ Should public figures have a different priority from the "average person"? ${ }^{18}$ Others have argued that demand side management decisions be used. ${ }^{19}$

In Canada a survey of transplant clinicians found that severity of disease and urgency were the most important criteria for listing patients whereas alcoholism, non-compliance and drug addiction, and those indications associated with a poor survival after transplant such as being positive for HIV and hepatitis $\mathrm{B}$ viral disease were seen as contraindications. ${ }^{20}$

\section{Public opinion}

The Oregon Health Services Commission asked the public to rank 714 condition-treatment pairs. ${ }^{7}$ Liver transplantation for cirrhosis not related to alcohol use was ranked 364 (just above hip replacement for osteoarthritis) whereas transplantation for alcohol related liver disease was 695 (just above in vitro fertilisation for tubal dysfunction). In a smaller study 380 prospective jurors were asked to distribute livers among patients grouped according to prognosis. ${ }^{21}$ It was found that while prognosis was an important factor in the allocation of donor livers few were willing to base allocation solely on the basis of maximum survival. Some groups have attempted to involve patients in the selection process for renal transplantation, but this is not without problems. ${ }^{22}$

Ethical guidelines indicate that patients should be treated solely on the basis of medical need ${ }^{14}$ and that behavioural patterns should not be considered. This dichotomy between ethical issues and public perception is well illustrated in the debate about transplantation for patients with alcoholic liver disease; survival and use of resources in patients grafted for alcoholic liver disease is similar to that in patients grafted for other causes of cirrhosis, ${ }^{23}$ and although up to $80 \%$ of patients return to some degree of alcohol consumption, graft damage (due to alcohol toxicity or non-compliance) is low. ${ }^{24}$ The ethical issues of transplantation for patients with alcohol related liver disease have been recently reviewed..$^{25}$ 
It is important that these observations are put into context: the clinical case histories, all based on real patients, were selected to prompt value judgments to estimate the value placed by the correspondents on factors such as "antisocial behaviour"-criminal behaviour and drug or alcohol misuse. The general public, unlike the clinicians, have probably not considered in depth the implications of donor shortage; furthermore, the case histories had to be brief and oversimplified. It was, in part, for this reason that we arranged for two focus groups. There are methodological concerns too. We used quota rather than random sampling; random sampling is purer but requires more respondents and more resources. The quota sampling used has been found to be robust and consistent over time.

We are grateful to all those who helped by taking part in this survey. We thank Miss Jayne Folwarski, Queen Elizabeth Hospital, Birmingham, for facilitating the study and $\mathrm{Mr}$ Brian Gosschalk, managing director, MORI, for his help and support.

Contributors: JN initiated the project and developed the ideas with DA and PMacM; the questionnaires were developed with AM and MS, who conducted the focus groups and analysed the findings.

Funding: Liver Research Trust.

Conflict of interest: MORI was paid by Birmingham Liver Unit to carry out the study.

1 UKTSSA. Transplant activity 1996. Bristol:UKTSSA, 1996.

2 United Network for Organ Sharing, Annual report 1997. Richmond VA:UNOS, 1998

3 Hauptman PJ, O'Connor K. Procurement and allocation of solid organs for transplantation. N Engl J Med 1997;336:422-31.

4 Steinbrook R. Allocating livers-devising a fair system. $N$ Engl J Med 1997;336:436-8

5 Neuberger J, Lake J. Allocating donor livers. BMJ 1997;314:1140-1.

6 World Health Organisation. Guiding principles on human organ transplantation. Lancet 1991;337:1470-1.
7 Dixon J, Welch HG. Priority setting: lessons from Oregon. Lancet 1991;337:891-4

8 Smith R. Rationing health care: moving the debate forward. $B M J$ 1996;312:1553.

9 Light DW. The real ethics of rationing. $B M J$ 1997;315:112-5.

10 Lenaghan J. Central government should have a greater role in rationing decisions. The case for. $B M J$ 1997;314:967-70.

11 Harrison S. Central government should have a greater role in rationing decisions. The case against. BMJ 1997;314:970-3

12 Stewart J, Kendall E, Coote A. Citizens'juries. London: Institute for Publi Policy Research, 1994.

13 Peters TG, Kittur DS, Mcgaw LJ, First MR, Nelson EW. Organ donors and non-donors-an American dilemma. Arch Intern Med 1996;156:2419-24.

14 Council on Ethical and Judicial Affairs, American Medical Association. Ethical demand for liver transplantation. Clin Transplant 1997;11:49-55.

15 Eghtesad B, Bronsther O, Irish W, Casavilla A, Abu Elmagd K, van Thiel $\mathrm{D}$, et al. Disease gravity and urgency of need as guide-lines for liver allocation. Hepatology 1994;20:56-8.

16 Williams A. The rationing debate: rationing health care by age. The case for. BMJ 1997;314:820-2.

17 Grimley Evans J. The rationing debate: rationing health care by age. The case against. $B M J 1997 ; 314: 822-5$

18 Altman LK. Defending tough decisions in a case open to hindsight. New York Times 1995 August 15; (col 1).

19 Ferguson M, Ferguson R. Rescuing Prometheus: a policy proposal to alleviate excess considerations in the allocation of organs and other scarce medical resources among patients. Arch Intern Med 1995;155: 29-34.

20 Mullen MA, Kohut N, Sam M, Blendis L, Singer P. Access to adult liver transplantation-a survey and ethical analysis. Can Med Assoc J 1996; $154: 337-49$

21 Ubel P, Loewenstein G. Public perceptions of the importance of prognosis in allocating transplantable livers to children. Med Decis Making 1996;16:234-41.

22 Ahn J, Homberger J. Involving patients in the cadaveric kidney transplant allocation process: a decision-theoretic perspective. Management Sci 1996;42:629-41.

23 Wiesner RH, Lombardero M, Lake J, Everhart J, Detre K. Liver transplantation for end-stage alcoholic liver disease: an assessment of outcomes. Liver Transplant Surg 1997;3:231-9.

24 Neuberger J, Tang H. Relapse after transplantation. Liver Transplant Surg 1997;3:275-9.

25 Benjamin M. Transplantation for alcoholic liver disease: the ethical issues. Liver Transplant Surg 199;3:337-42.

26 Ubel PA. Transplantation in alcoholics: separating prognosis and responsibility from social biases. Liver Transplant Surg 1997;3:343-6.

(Accepted 6 April 1998)

\section{Risk factors for development of sexually abusive behaviour in sexually victimised adolescent boys: cross sectional study}

David Skuse, Arnon Bentovim, Jill Hodges, Jim Stevenson, Chriso Andreou, Monica Lanyado, Michelle New, Bryn Williams, Dean McMillan

\section{Abstract}

Objective: To identify factors that may increase the risk of a sexually victimised adolescent boy developing sexually abusive behaviour.

Design: Sexually victimised boys who had sexually abused other children were compared with sexually victimised boys who had not done so.

Setting: Social services departments in south east England were invited to refer sexually abused and sexually abusing boys to a London postgraduate teaching hospital.

Subjects: 25 adolescent boys aged between 11 years and 15 years and 11 months.

Main outcome measures: Adjusted odds ratios estimated from unconditional logistic regression.
Results: Unadjusted odds rations for witnessing (8.1) as well as experiencing (18.0) intrafamilial violence and discontinuity of care (7.2) discriminated boys who had sexually abused from others who were solely victims of sexual abuse. Only the adjusted odds ratios for witnessing intrafamilial violence (39.7)

discriminated the two groups.

Conclusions: The risk of adolescent boys who have been victims of sexual abuse engaging in sexually abusive behaviour towards other children is increased by life circumstances which may be unrelated directly to the original abusive experience, in particular exposure to a climate of intrafamilial violence. Our findings have implications for the management of boys found to have been sexually abused and raise important questions about the possibility of secondary prevention of subsequent abusive behaviour in those at greatest risk.
Behavioural Sciences Unit, Institute of Child Health, London WC1N 1EH

David Skuse, professor of behavioural sciences Bryn Williams, research psychologist Dean McMillan, research assistant

continued over

BMJ 1998;317:175-9 